\title{
Clinical algorithms for the screening of Chlamydia trachomatis in Turkish women
}

\author{
Carine Ronsmans, Aysen Bulut, Nuray Yolsal, Ali Agaçfidan, Veronique Filippi
}

\begin{abstract}
Objective: To test the diagnostic validity of clinical algorithms for the detection of Chlamydia trachomatis in an urban population of married women in Turkey.

Design: Cross-sectional population-based survey.

Subjects: A systematic sample of 867 women who reported the use of contraceptive methods.

Main outcome measures: Sensitivity, specificity and positive predictive value of clinical algorithms for the diagnosis of $C$ trachomatis.

Results: $C$ trachomatis was diagnosed in $4.89 \%$ of the women. The WHO algorithm for use in settings where no vaginal examination could be performed had a sensitivity of $9 \%$ and a specificity of $96 \%$. The corresponding figures for the WHO algorithm incorporating the findings of a speculum examination were $47 \%$ and $56 \%$ respectively. Algorithms incorporating symptoms or signs other than those suggested by the WHO did not yield satisfactory standards of validity.

Conclusions: The findings of this study do not support the widespread introduction of the use of clinical decision models for screening of women for chlamydia infection in primary health care settings such as family planning or antenatal clinics. The large number of false positive results with the use of the clinical algorithms tested in this study would cause unnecessary costs to the health system and unnecessary interventions to the women treated.

(Genitourin Med 1996;72:182-186)
\end{abstract}

Keywords: Chlamydia trachomatis; algorithm; screening

Maternal and Child Epidemiology Unit, London School of Hygiene and Tropical Medicine, Keppel St, London WC1E 7HT, UK

C Ronsmans

V Filippi

Institute of Child

Health, University of Istanbul, Istanbul,

Turkey

A Bulut

Department of Public Health, Istanbul Faculty of Medicine, Istanbul, Turkey N Yolsal

Department of Microbiology, Istanbu Faculty of Medicine, Istanbul, Turkey A Agaçfidan

Address correspondence to: Carine Ronsmans.

Accepted for publication 15 January 1996

\section{Introduction}

Sexually transmitted diseases (STDs), particularly those due to Chlamydia trachomatis and Neisseria gonorrhoeae pose a major threat to the health of men and women throughout the world. In women, infections due to $C$ trachomatis may cause severe acute complications such as pelvic inflammatory disease leading to serious sequelae including premature rupture of membranes, ectopic pregnancy and infertility. ${ }^{1}$

The diagnosis of STDs often requires the use of sophisticated and expensive laboratory equipment which may not be available in many settings, particularly in the developing world. For that reason, the World Health Organization (WHO) has developed simple diagnostic models in which symptoms reported by the woman and/or signs observed by the physician are used to arrive at a diagnosis. ${ }^{2}$ Recently, the diagnostic algorithms have been revisited and an initial assessment of the woman's risk status based on her age, marital status and characteristics of her sexual partner(s) has been added to the algorithm. ${ }^{34}$ Previous research has suggested that the inclusion of a risk assessment adapted to the local epidemiological context of STDs may increase the predictive power for the diagnosis of cervicitis due to $N$ gonorrhoeae and $C$ trachoma tis. ${ }^{5-8}$ Although the algorithms have been developed for the diagnosis of STDs in women who are seeking care for symptoms of vaginal discharge and/or lower abdominal pain, their use as a screening tool in women attending antenatal or family planning clinics has been proposed. ${ }^{4910}$ Little evidence, how- ever, exists on the validity of such algorithms for active case finding in a population-based sample of women. For developing countries, the available evidence suggests that the diag nostic validity of clinical algorithms for the detection of $N$ gonorrhoeae and $C$ trachomatis may be poor. ${ }^{58}$

The objectives of this study were to test the diagnostic validity of clinical algorithms for the detection of $C$ trachomatis in an urban population of married women in Turkey.

\section{Methods}

The study was carried out in Cobançesme, a rapidly growing suburb in the western part of Istanbul, the metropolis of Turkey. In 1986, all the households residing in the area were listed, and an update of the population has been maintained since by the Maternal and Child Health and Family Planning ( $\mathrm{MCH} /$ FP) Centre. In 1993, the population of Cobançesme was approximately 25000 .

A systematic sample of 1204 currently married women between the ages of 15 and 44 years who reported they had ever tried to avoid a pregnancy was selected from the household register. Of these, 337 women were excluded because of out-migration (197), refusal (56), non-eligibility (33) and current pregnancy (51). The remaining women were visited at their home by two female interviewers, their socio-demographic characteristics and potential risk determinants for reproductive tract infections (RTIs) were noted and they were invited to attend the $\mathrm{MCH} / \mathrm{FP}$ centre for further interview and examination by a physician. 
(a) Algorithm if vaginal examination possible

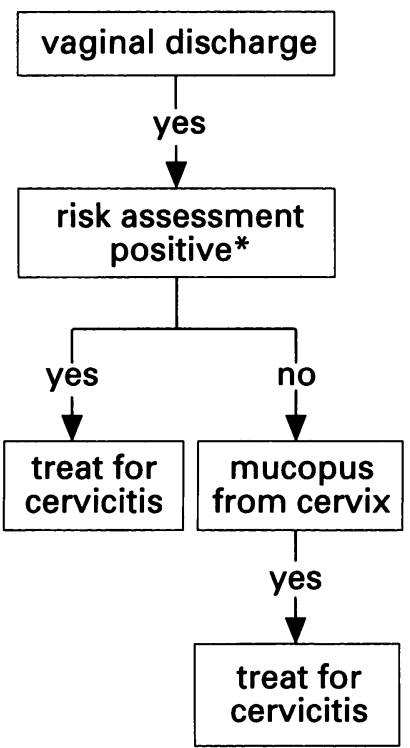

* positive = partner symptomatic, or any two of: age < 21 years; single; $>1$ partner; new partner in past 3 months

† pelvic inflammatory disease

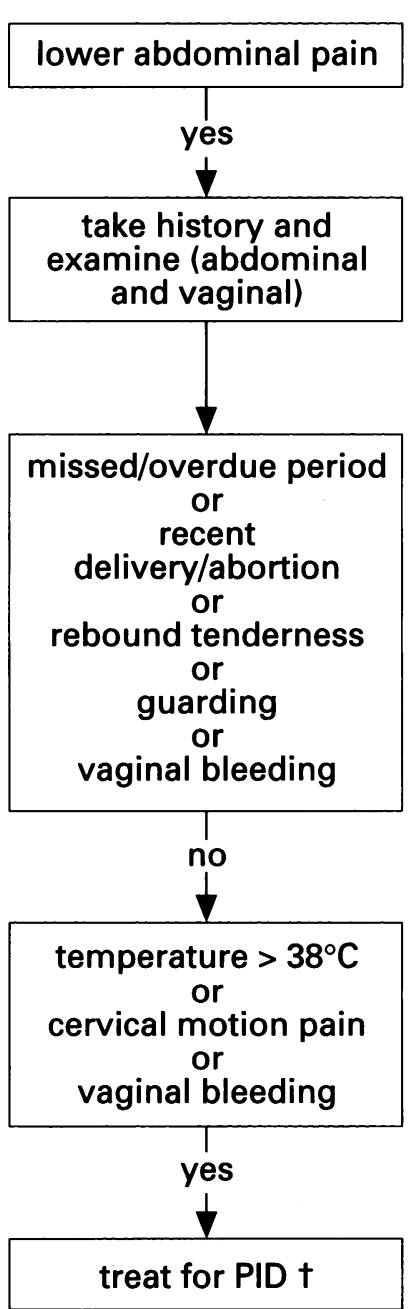

(b)

\section{Algorithm if vaginal examination not possible}

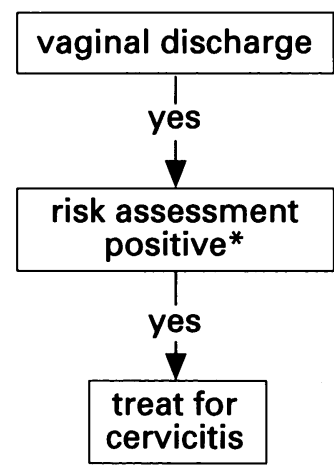

* positive = partner symptomatic, or any two of: age $<21$ years; single; > 1 partner; new partner in past 3 months

Clinical algorithm for the diagnosis of $C$ trachomatis in women, based on the WHOalgorithm for vaginal discharge and lower abdominal pain.

Of the 867 women who were invited to attend the MCH/FP centre, 171 did not come to the clinic.

Between May 1993 and February 1994, 696 women were seen by three female primary care physicians in the $\mathrm{MCH} / \mathrm{FP}$ centre. Two physicians ( $\mathrm{AB}$ and $\mathrm{NY}$ ) with extensive training and clinical experience in the diagnosis of RTIs carried out $43 \%$ of the examinations and one junior physician who had received one months' training in diagnosing RTIs carried out the remainder of the examinations. The physicians used a structured questionnaire to record the reproductive symptoms described by the women and performed a physical examination which included an abdominal, a speculum, and a bimanual examination. The amount, consistency and colour of the discharge within the vagina were recorded by simple inspection and, in case of uncertainty, by using a swab test ${ }^{11}$; the presence of cervical ectopy, easily induced endocervical bleeding and tenderness on moving the cervix were also noted.

A sample of the vaginal discharge was removed from the posterior fornix with a swab and tested for $\mathrm{pH}$, and another sample was mixed with a drop of $10 \% \mathrm{KOH}$ to assess the presence of a fishy odour. These samples were gram-stained and examined microscopically for the presence of clue cells, polymorphonuclear leucocytes, and fungal forms. Vaginal swabs from the vaginal side walls were cultured onto Trichomonas Liquid Medium (Oxoid-code: CM161) and examined microscopically for motile trichomonads. Women were considered infected with trichomonas if the vaginal culture was positive. A woman was diagnosed as having bacterial vaginosis if she presented three of the following findings: white and "mucoid or milky" and "moderate or abundant" vaginal discharge; vaginal $\mathrm{ph}>$ 4.5; positive $\mathrm{KOH}$ test; presence of clue cells in the gram stain. ${ }^{12}$

Cervical smears were examined microscopically for the presence of leucocytes and were fixed for PAP smear examination. Samples taken from the cleaned endocervix were assayed for $C$ trachomatis, using an enzyme linked immunoassay (EIA) (IDEIA Chlamydia, DAKO Diagnostics Ltd, Cambridgeshire, UK). The positive results obtained by EIA were confirmed by direct fluorescent assay (DFA) (Micro Trak, Syva Co, Palo Alto, CA). One woman had to be excluded from the analysis because of invalid endocervical samples for $C$ trachomatis.

Two clinical algorithms were assessed, one for use in settings where a vaginal examination is not possible and one for use in settings where a speculum examination is possible (fig). ${ }^{3}$ The algorithms aim at identifying women with cervicitis or pelvic inflammatory disease (PID) due to $C$ trachomatis and/or $N$ gonorrhoeae. In first level settings where a vaginal examination can not be done, women are diagnosed with cervicitis if they complain of vaginal discharge and are at high risk of STDs. Women are considered at high risk of STDs when their partner is symptomatic or when they have any two of the following characteristics: they are younger than 21 ; they are single; they have more than one partner; or they have a new partner in the last 3 months. In settings where a clinical examination including a vaginal 
Table 1 Selected characteristics of women with Chlamydia trachomatis in Instanbul, Turkey

\begin{tabular}{|c|c|c|c|}
\hline \multirow[b]{2}{*}{ Characteristic } & \multicolumn{2}{|c|}{ Percent with characteristic } & \multirow[b]{2}{*}{$\begin{array}{l}\text { Odds Ratio } \\
95 \% \text { confidence }\end{array}$} \\
\hline & $\begin{array}{l}\text { Women with } \\
\text { C. trachomatis } \\
(n=34)\end{array}$ & $\begin{array}{l}\text { Women without internal } \\
\text { C. trachomatis } \\
(n=661)\end{array}$ & \\
\hline $\begin{array}{l}\text { Risk determinants } \\
\text { Age }<21 \text { years } \\
\text { Husband discharge } \\
\text { IUD use } \\
\text { Condom use } \\
\text { Pill use } \\
\text { Vaginal “douching" }\end{array}$ & $\begin{array}{r}2 \cdot 94 \\
11 \cdot 76 \\
29 \cdot 41 \\
8 \cdot 82 \\
8 \cdot 82 \\
82 \cdot 35\end{array}$ & $\begin{array}{r}2 \cdot 27 \\
5 \cdot 34 \\
27 \cdot 77 \\
9 \cdot 71 \\
5 \cdot 16 \\
87 \cdot 54\end{array}$ & $\begin{array}{l}1.30(0.17-10.18) \\
2.37(0.79-7.09) \\
1.08(0.51-2.31) \\
0.90(0.27-3.03) \\
1.78(0.52-6.11) \\
0.66(0.27-1.65)\end{array}$ \\
\hline $\begin{array}{l}\text { Reported symptoms } \\
\text { Abnormal vaginal discharge } \\
\text { Vaginal itching } \\
\text { Malodorous discharge } \\
\text { Profuse discharge } \\
\text { Yellow-green discharge } \\
\text { Urinary complaints } \\
\text { Dyspareunia } \\
\text { Lower back pain } \\
\text { Lower abdominal pain }\end{array}$ & $\begin{array}{l}55 \cdot 88 \\
14 \cdot 71 \\
23 \cdot 53 \\
23 \cdot 53 \\
11 \cdot 76 \\
29 \cdot 41 \\
35 \cdot 29 \\
67 \cdot 65 \\
55 \cdot 88\end{array}$ & $\begin{array}{l}56 \cdot 28 \\
16 \cdot 26 \\
25 \cdot 15 \\
11 \cdot 04 \\
12 \cdot 88 \\
38 \cdot 18 \\
37 \cdot 35 \\
69 \cdot 59 \\
54 \cdot 85\end{array}$ & $\begin{array}{l}0.98(0.49-1.97) \\
0.89(0.34-2.35) \\
0.91(0.41-2.06) \\
2.48 \ddagger(1.08-5.68) \\
0.90(0.31-2.62) \\
0.67(0.32-1.43) \\
0.91(0.44-1.88) \\
0.91(0.44-1.91) \\
1.04(0.52-2.09)\end{array}$ \\
\hline $\begin{array}{l}\text { Clinical examination } \\
\text { Abnormal vaginal discharge } \\
\text { Profuse discharge } \\
\text { Cheesy (clumped) discharge } \\
\text { Anine odour } \\
\text { Endocervical mucopus } \\
\text { Cervical ectopy } \\
\text { Cervical friability } \\
\text { Pain on cervical motion }\end{array}$ & $\begin{array}{r}52 \cdot 94 \\
2 \cdot 94 \\
8 \cdot 82 \\
18 \cdot 18 \\
11 \cdot 76 \\
26 \cdot 47 \\
35 \cdot 29 \\
17 \cdot 65\end{array}$ & $\begin{array}{r}50 \cdot 23 \\
4 \cdot 12 \\
4 \cdot 57 \\
16 \cdot 07 \\
14 \cdot 33 \\
9 \cdot 98 \\
29 \cdot 20 \\
22 \cdot 61\end{array}$ & $\begin{array}{l}1.11(0.56-2 \cdot 22) \\
0.71(0.09-5 \cdot 36) \\
2 \cdot 02(0.58-6.99) \\
1.16(0.47-2 \cdot 88) \\
0 \cdot 80(0.27-2 \cdot 31) \\
3 \cdot 24((1 \cdot 45-7 \cdot 25) \\
1.32(0.64-2 \cdot 73) \\
0.73(0.30-1 \cdot 80)\end{array}$ \\
\hline $\begin{array}{l}\text { Laboratory results } \\
\text { Microscopy } \\
\text { Leucocytes }\left(\geqslant 10 / \mathrm{HPF}^{\star}\right) \\
\text { PMNt }(\geqslant 30 / \mathrm{HPF}) \\
\text { Clue cells }\end{array}$ & $\begin{array}{r}82 \cdot 35 \\
47 \cdot 06 \\
2 \cdot 94\end{array}$ & $\begin{array}{r}60 \cdot 82 \\
23 \cdot 60 \\
4 \cdot 84\end{array}$ & $\begin{array}{l}3.01 \oint(1.23-7 \cdot 36) \\
2.88 \oint(1.43-5 \cdot 78) \\
0.60(0.08-4.49)\end{array}$ \\
\hline
\end{tabular}

and an abdominal examination can be performed, women are diagnosed with cervicitis if they complain of vaginal discharge and are either at high risk of STDs or at low risk of STDs but the speculum exam reveals the presence of mucopurulent discharge from the cervix. In the latter setting, women who complain of lower abdominal pain are diagnosed with PID if they have a fever, pain on cervical motion, or vaginal discharge.

In this study, the standard against which the algorithms were assessed was a positive assay for $C$ trachomatis. The performance of the algorithms were tested by simulating the decision trees using the distribution of the signs and symptoms observed in the sample and by calculating the sensitivity, specificity, and positive predictive value of a combination of signs and symptoms for the diagnosis of $C$ trachomatis. Significant associations were tested using a chi square or a Fisher's exact test for comparing proportions.

In an attempt to improve the performance of the clinical algorithms, alternative algorithms were constructed based on the findings from the univariate analysis of the association between risk determinants, signs or symptoms and chlamydia infection. Variables that were found to be associated with chlamydia infection in the univariate analysis were incorporated in an algorithm, either alone or in combination, and their sensitivity, specificity, and positive predictive value for the diagnosis of $C$ trachomatis was assessed.

\section{Results}

The 695 women who participated in the study had a mean age of 31.95 years (standard deviation: 6.21 ); a mean parity of 2.72 (SD:1.46); and $12.4 \%$ had received a secondary school education. In comparison, the 171 women who were not examined had a mean age of $29 \cdot 12$ years (SD:5.85); a mean parity of $2 \cdot 27$ (SD:1.33); and $24 \%$ had been to secondary school.

$C$ trachomatis antigens were isolated in 34 $(4.89 \%)$ of 695 women. The prevalence of $C$ albicans, Trichomonas vaginalis and bacterial vaginosis was $5 \cdot 18(n=36), 2 \cdot 88 \%(n=20)$ and $4.46 \%(n=31)$ respectively. Among the women with chlamydial infections, 2 also had candidiasis, 2 also had trichomoniasis and 2 also had bacterial vaginosis.

The potential risk determinants, reported symptoms, signs on clinical examination and laboratory results for chlamydial infection are presented in table 1. Potential determinants for high risk of STDs such as young age or repeated vaginal douching were not associated with infection due to $C$ trachomatis. Women with infection due to $C$ trachomatis reported more often the presence of urethral discharge in their husband than those without, but this difference was not significant (odds ratio 2.37, $95 \%$ confidence interval $0 \cdot 79-7 \cdot 09)$. More than half of the women reported abnormal vaginal discharge or lower abdominal pain, but neither of these symptoms were associated with chlamydial infection, except for profuse discharge which was more commonly reported by women with chlamydial infection (odds ratio $2 \cdot 48,95 \%$ CI 1.08-5.68).

The physicians reported a higher prevalence of cervical ectopy in women infected with $C$ trachomatis. Leucocytes and neutrophils were more commonly found in the discharge of women infected with $C$ trachomatis.

The sensitivity, specificity and positive predictive value of the WHO algorithms are shown in table 2 . In settings where a speculum

Table 2 Sensitivity, specificity and positive predictive value of algorithms for the screening of $C$ trachomatis

\begin{tabular}{|c|c|c|c|c|c|c|}
\hline Screening algorithm & $\begin{array}{l}\text { Number of } \\
\text { women * }\end{array}$ & $\begin{array}{l}\text { Number of } \\
\text { infected } \\
\text { women }\end{array}$ & $\begin{array}{l}\text { Number of } \\
\text { cases } \\
\text { detected }\end{array}$ & $\begin{array}{l}\text { Sensitivity } \\
(\%)\end{array}$ & $\begin{array}{l}\text { Specificity } \\
(\%)\end{array}$ & $\begin{array}{l}\text { Positive } \\
\text { Predictive } \\
\text { Value (\%) }\end{array}$ \\
\hline $\begin{array}{l}\text { WHO-algorithms } \\
\text { Without vaginal examination } \\
\text { With vaginal examination }\end{array}$ & $\begin{array}{l}690 \\
683\end{array}$ & $\begin{array}{l}34 \\
34\end{array}$ & $\begin{array}{r}3 \\
16\end{array}$ & $\begin{array}{r}8 \cdot 82 \\
47 \cdot 06\end{array}$ & $\begin{array}{l}96 \cdot 19 \\
56 \cdot 09\end{array}$ & $\begin{array}{r}10 \cdot 71 \\
5 \cdot 32\end{array}$ \\
\hline $\begin{array}{l}\text { Alternative algorithms } \\
\text { Reported discharge in husband } \\
\text { Reported discharge in husband } \\
\text { and age }<25 \text { years } \\
\text { Reported profuse discharge } \\
\text { Reported profuse discharge } \\
\text { and cervical ectopy }\end{array}$ & $\begin{array}{l}690 \\
690 \\
686 \\
686\end{array}$ & $\begin{array}{l}34 \\
34 \\
34 \\
34\end{array}$ & $\begin{array}{l}4 \\
0 \\
8 \\
1\end{array}$ & $\begin{array}{r}11 \cdot 76 \\
0 \cdot 00 \\
23 \cdot 53 \\
2 \cdot 94\end{array}$ & $\begin{array}{l}94 \cdot 66 \\
99 \cdot 54 \\
88 \cdot 96 \\
98 \cdot 47\end{array}$ & $\begin{array}{r}10 \cdot 26 \\
0 \cdot 00 \\
10 \cdot 00 \\
7 \cdot 36\end{array}$ \\
\hline
\end{tabular}

*The number of women for which information on all the relevant variables was available. 
examination can not be performed, the algorithm had a sensitivity of $8 \cdot 82 \%$ and a specificity of $96 \cdot 19 \%$ for the screening of women for chlamydial infection. Of the 28 women who satisfied the algorithm, 25 did not test positive for the EIA. Adding the findings of a speculum examination increased the sensitivity to $47 \cdot 06 \%$ and decreased the specificity to $56.09 \%$. With the latter algorithm, only 16 out of the 301 women who satisfied the algorithm would effectively have the disease (positive predictive value $=5 \cdot 32 \%$ ) .

Multiple alternative algorithms were tested, of which only four are presented here (table 2 ). Women were regarded as infected with $C$ trachomatis if (1) they reported urethral discharge in their husband; (2) they reported urethral discharge in their husband and were less than 25 years old; (3) they reported profuse vaginal discharge; and (4) they reported profuse vaginal discharge and cervical ectopy was found during vaginal examination. None of the algorithms yielded satisfactory standards of validity. The sensitivity was very low, ranging between 0 and $24 \%$. This low sensitivity is due to the low prevalence of any of the tested characteristics amongst women with chlamydial infection. The positive predictive value was equally low, ranging from 0 to $10 \%$.

\section{Discussion}

In this population, reproductive symptoms reported by the woman were very poor predictors of chlamydial infection. Although reports of vaginal discharge and abdominal pain were very common, they were not indicative of infection with $C$ trachomatis, and this is consistent with the findings from other studies. ${ }^{5-8} 13$

Clinical signs such as mucopurulent discharge from the cervix, ${ }^{614}$ induced endocervical bleeding ${ }^{614}$ and cervical ectopy ${ }^{7}$ are usually more predictive of chlamydial infection than reported symptoms, although their low prevalence makes them not very useful for screening purposes. ${ }^{5}$ Cervical ectopy was strongly associated with chlamydial infection in this study, but was only present in $26 \%$ of the chlamydial infections, hence cervical ectopy on clinical examination would be too insensitive for use in the screening of women for chlamydial infection.

Mucopurulent discharge from the cervix, the key sign by which clinical algorithms usually distinguish women with chlamydial infection from those without, ${ }^{2411}$ was not found to be a good predictor of chlamydial infection in this study. The physicians carrying out the clinical examination were experienced in examining women for signs of STDs, but only performed the recommended swab test if they were uncertain about the presence of mucopurulent discharge on inspection of the cervix. Objective signs of cervical inflammation may be difficult to diagnose because of changes in the cervix over the reproductive period and with the menstrual cycle. ${ }^{15}$ Mucopurulent discharge was associated with trichomoniasis (data not shown), which suggests that the yellow-green discharge commonly associated with trichomonas ${ }^{16}$ may be difficult to distinguish from "mucopurulent" discharge.

Incorporation of one or more risk determinants into the algorithm such as young age, ${ }^{5814}$ being unmarried, ${ }^{58}$ having had more than one sexual partner in a relatively recent period ${ }^{5-813}$ or having changed partners recently ${ }^{713}$ usually increases the sensitivity and specificity of the algorithm. In this population, risk assessment questions did not help distinguish chlamydial infections from other infections. All the women were married and the majority of the women examined were older than 25 years, and age was thus not a predictor of chlamydial infection. A report of discharge in the husband was too uncommon to be of value for screening purposes, and it was not deemed acceptable to ask questions about the number of sexual partners. If risk-criteria based on the local epidemiological profile and on behavioural rather than clinical characteristics are to be recommended for inclusion in algorithms for the diagnosis of RTI, care will have to be taken to assess the reliability and validity of the risk-criteria in the specific context in which they are to be applied.

This study did not test for the presence of $N$ gonorrhoeae, one of the major causes of cervicitis in women. Since the WHO algorithms aim at identifying women with cervicitis rather than women with chlamydial infection, the women with gonococcal cervicitis may have been incorrectly classified in this study, and the validity of the algorithms may have been mis-specified. Other studies testing for the presence of $N$ gonorrhoeae amongst Turkish women, however, have found no or very low prevalences of gonococcal infections amongst women ${ }^{17-19}$ and it is unlikely that this misclassification would have caused a major bias in the estimates of sensitivity and specificity in this study. Other studies assessing the validity of clinical algorithms for the diagnosis of both chlamydial and gonococcal infections have also yielded very poor results in low prevalence populations. ${ }^{58}$

The enzyme immunoassay used as a standard for the diagnosis of chlamydial infection in this study has a specificity approaching $100 \%$ for the detection of $C$ trachomatis, but the sensitivity may be poor. ${ }^{20} \mathrm{~A}$ fraction of the women with chlamydial infection may have been wrongly classified as not having the disease, biasing the estimates of the specificity of the clinical algorithms. The magnitude of this bias, however, is small, given the low prevalence of chlamydial infection in this population.

The fact that one fifth of the women refused to participate in the study is a matter for concern, particularly since efforts were made to prevent such a problem. This high nonresponse rate poses a threat not only to the validity of the results but also to the effective control of STDs. The women who did not participate were younger and more educated than those who did, and did not want to be examined because they perceived they had no problems. Although impossible to ascertain, their younger age may have put them at higher 
risk for STDs, particularly to infections due to $C$ trachomatis. ${ }^{5}$ That women may perceive STD services as stigmatising is well known, ${ }^{21}$ but it is particularly worrying that the young and possibly most vulnerable group are the ones refusing to be examined.

The findings of this study do not support the widespread introduction of the use of clinical decision models for screening of women for $C$ trachomatis in primary health care settings such as family planning or antenatal clinics. The large number of false positive test results with the use of any of the clinical algorithms tested in this study would cause unnecessary costs to the health system and to the women treated. Finding rapid, simple and cheap tests for the diagnosis of $C$ trachomatis, such as the recently developed urine assay ${ }^{22}$ remains a major priority for reproductive health research.

We thank F Kayaturk, H Nalbant, S Advan, and M Salcioglu for their help with the data collection; $K$ Toreci and U Gurler from the Microbiology Department of the Istanbul Medical School; and Wendy Graham and Bea Vuylsteke for their comments on an earlier draft of this paper. This study was funded by grant from the Special Programme of Research Developmen and Research Training in Human Reproduction of the World Health Organization, and was one of the five collaborative studies undertaken within an international programme of research on Methods for Measuring Maternal Health in Developing Countries, coordinated by the Maternal and Child Epidemiology Unit, and funded by the British Overseas Development Administration.

1 Robertson DHH, McMillan A, Young H. Non-gonococcal urethritis, chlamydial infections and other related condiurethritis, chlamydial infections and other related conditions. In: Robertson DHH, McMillan A, Young H, eds. Clinical Practice in Sexually Transmissible Dis

2 World Health Organization. Report of a WHO study group. Management of patients with sexually transmitted diseases. WHO Technical Report Series 810. Geneva World Health Organization, 1991.

3 World Health Organization. Recommendations for the management of sexually transmitted diseases. GPA TEM/94.1 Geneva: World Health Organization, 1994

4 Lande R. Controlling Sexually Transmitted Diseases. Population Reports. Series L: Issues in World Health, 1993;9:1-31.

5 Vuylsteke B, Laga $M$, Alary $M$, et al. Clinical algorithms for the screening of women with gonococcal and chlamydial the screening of women with gonococcal and chlamydial infection: evaluation of pregnant wom

6 Braddick MR, Ndinya-Achola JO, Mirza NB, et al. Towards developing a diagnostic algorithm for Chlamydia trachomatis and Neisseria gonorrhoeae cervicitis in pregnancy. Genitourin Med, 1990;66:62-5.

7 Johnson BA, Poses RM, Fortner CA, Meier FA, Dalton
HP. Derivation and validation of a clinical diagnostic model for chlamydial cervical infection in university women. $\mathscr{F} A M A$ 1990;264:3161-5.

8 Mayaud $\mathrm{P}$, Grosskurth $\mathrm{H}$, Changalucha J, Todd J, West B, Gabone R, Senkoro K, Rusizoka M, Laga M, Hayes $R$, Mabey D. Risk assessment and other screening options for gonorrhoea and chlamydial infections in rural Tanzanian antenatal clinic attendees. Bull World Health Organ 1995;73:621-30.

9 World Health Organization. Practical Guide. Care of mother and baby at the health centre: a practical guide. Geneva: Maternal Health and Safe Motherhood Program, Division of Family Health, World Health Organization, 1994.

10 Petta CA. Management of common genital infections. IPPF Medical Bulletin 1994;28:1-3.

11 Brunham RC, Paavonen J, Stevens CE et al. Mucopurulent cervicitis: the ignored counterpart in women of urethritis in men. N Engl ₹ Med 1984;311:1-6.

12 Amsel R, Totten PA, Spiegel CA, Chen KC, Eschenbach $D$, Holmes KK. Nonspecific vaginitis: Diagnostic criteria and microbial and epidemiologic associations. $A m \mathcal{F} \mathrm{Med}$ 1983;74:14-22.

13 Addiss DG, Vaughn ML, Golubjatnikov R, Pfister J, Kurtycz DFI, Davis JP. Chlamydia trachomatis infection in women attending urban midwestern family planning and community health clinics: risk factors, selective screening, and evaluation of non-culture techniques. Sex Transm Dis 1990;17:138-46.

14 Handsfield $\mathrm{HH}$, Jasman LL, Roberts PL, Hanson VW, Kothenbeutel RL, Stamm WE. Criteria for selective screening for Chlamydia trachomatis infection in women screening for Chlamydia trachomatis infection in women
attending family planning clinics. $\mathscr{F} A M A$ 1986;255: attending

15 Holmes KK. Lower genital tract infections in women: Cystitis, urethritis, vulvovaginitis, and cervicitis. In: Holmes KK, Mardh P, Sparling PF, Wiesner PJ, eds Sexually Transmitted Diseases. New York: McGraw-Hill, 1990.

16 Rein MF and Muller M. Trichomonas vaginalis and trichomoniasis. In: Holmes KK, Mardh P, Sparling PF, Wiesner PI, eds. Sexually Transmitted Diseases. New York: McGraw-Hill, 1990.

17 Genç M, Agaçfidan A, Yeğenoğlu Y, Turan Ö, Kuru U, Mårdh PA. Screening for Chlamydia trachomatis and Neisseria gonorhhoeae in pregnant Turkish women. Eur $\mathcal{F}$ Neisseria gonorrhoeae in pregnant Turkish
Clin Microbiol Infect Dis 1993;12:395-6.

18 Özarm Microbiol Infect Dis 1993;12:395-6. O. The results of the first STD clinic in Turkey. In: Panconesi E, ed. Dermatology in Europe. Proceedings of Panconesi E, ed. Dermatology in Europe. Proceedings of the 1st Congress of the European Academy of Publications, 1994

19 Özarmaeğan G, Altinok T, Yeğenoğlu Y, Saylan T. Riskl Kadin Grubunda Neisseria gonorrhoeae, Chlamydia trachomatis ve Ureaplasma urealyticum Infeksiyonu Sikligi Klimik Derg, 1991;4:77-8(Turkish).

20 Bassiri M, Hu HY, Domeika MA, et al. Detection of Chlamydia trachomatis in urine specimens from women by ligase chain reaction. $\mathcal{F}$ Clin Microbiol 1995;33: by ligase

21 Laga $M$. Epidemiology and control of sexually transmitted diseases in developing countries. Sex Transm Dis 1994; 21(suppl.): $\$ 45-50$.

22 Lee HH, Chernesky MA, Schachter J, Burczak, Andrews WW, Muldoon S, Leckie G, Stamm WE. Diagnosis of Chlamydia trachomatis genitourinary infection in women by ligase chain reaction assay of urine. Lancet 1995;345 213-16. 